\title{
Results of slotted acetabular augmentation in adults with Crowe stage 1 and 2 hip dysplasia
}

\author{
Thomas Hacquart ${ }^{1}$, Roger Erivan ${ }^{1}$, Guillaume Villatte', Aurélien Mulliez', Stéphane Boisgard ${ }^{1}$, Stéphane Descamps ${ }^{1}$ \\ ${ }^{1}$ CHU Clermont \\ Keywords: congenital hip dysplasia, congenital hip displacement, congenital hip dislocation \\ https://doi.org/10.52965/001c.24439
}

\section{Orthopedic Reviews}

Vol. 13, Issue 1, 2021

\begin{abstract}
To determine the survival of slotted acetabular augmentation in adult dysplasia, we reviewed all cases operated on between 2002 and 2020 with clinical and radiological assessment and a 2.63 year minimum of follow-up.

Twenty-three patients were included, with 91\% of Crowe 1 hip dysplasia. Seven patients underwent THA at a mean $6.0 \pm 3.5$ years; 15 retained SAA without THA at a mean 9.5 years' follow-up; 1 was lost to follow-up. There was a significant improvement in PMA and HHS scores, with decreased pain. WOMAC and SF12 quality-of-life scores were moderate due to frequent pain. The patients with preoperative osteoarthritis showed little progression at seven years 'follow-up.

We concluded SAA is a corrective treatment for residual hip dysplasia. Its goal is to normalize joint loading by increasing the contact area and improving the lever arm of the hip. Its postponed onset of osteoarthritis and reduced pain, thereby allowing to postpone THA.
\end{abstract}

\section{INTRODUCTION}

Hip dysplasia is a complex developmental process. It is an architectural abnormality that affects $4 \%$ of the Caucasian population and is responsible for hip osteoarthritis. ${ }^{1}$ There are several classifications of congenital hip dysplasia in adults, Crowe's classification ${ }^{2}$ being the best known worldwide. Further measurements can be performed to stratify or grade the severity of hip dysplasia. ${ }^{3-5}$

Excessive hip-joint contact stress due to a small loadbearing area is an essential factor in the early development of osteoarthritis. ${ }^{3}$ Surgical treatment for the dysplastic hip is increasingly rare in adults but can use various techniques: Chiari osteotomy six or extra-articular augmentation of the acetabular roof. These procedures can relieve pain and postpone the development of osteoarthritis. Slotted acetabular augmentation (SAA) is a relatively simple method to increase congruent coverage of the femoral head. The principle consists of creating an extra-articular buttress, preventing further subluxation while potentially increasing the load-bearing area of the hip. ${ }^{6}$ But this kind of procedure is rarely used because of the good results of total hip arthroplasty. Thus, it seemed essential to assess this treatment.

The main objective of this study was to determine the survival of SAA for the treatment of residual hip dysplasia in adults.

The study hypothesis was that SAA enables total hip arthroplasty (THA) to be postponed.

\section{MATERIALS AND METHODS}

After approval from the Ethical Committee of our institutional Review Board (2019 / CE 16), a single-center retrospective study was carried out, and all participants obtained informed consent. Survival of SAA was analyzed in 23 patients undergoing SAA for hip dysplasia in our center from 2002 to 2017; 2 patients received bilateral SAA. Between January and February 2020, patients were seen to know whether they had undergone hip arthroplasty and for clinical and radiological review. Indications for SAA were hip pain lasting more than six months secondary to acetabular dysplasia, despite non-operative treatment.

This study included four men and 17 women, aged (mean $\pm \mathrm{SD}) 37 \pm 8.6$ years (range, 23-51 years) at the surgery. The mean body mass index (BMI) was $25.4 \pm 4.2$ (range, 18.2-36.3).

Dysplasia on the Crowe classification was grade 1 for 21 patients and grade 2 for two patients. 12 SAAs were on the right and 11 on the left sides.

Twenty-one hips had SAA. Two patients had associated femoral variation osteotomy. 2 patients had previous proximal femoral osteotomy. ${ }^{7} 2$ patients had a surgical history: 1 triple Chiari osteotomy 8 and 1 screw treatment of hip osteochondritis. There was one intraoperative complication (partial sciatic motor palsy) in the patient with a screw treatment of hip osteochondritis in childhood.

All patients were treated by the same SAA technique, ${ }^{6}$ with an iliac graft to the upper edge of the acetabulum performed by three senior surgeons. After surgery, walking was authorized without weight-bearing for six weeks.

Harris Hip Score (HHS) ${ }^{9}$ and Postel-Merle d'Aubigné 
Table 1. Comparison of the 22 SAAs followed up by clinical examination or telephone questionnaire with X-rays, and the 7 patients with subsequent THA.

\begin{tabular}{|c|c|c|c|}
\hline Characteristics & SAA & THA & P-value \\
\hline Patients ( $n=)$ & 13 & 7 & \\
\hline bilateral & 2 & 0 & \\
\hline Male (\%) & $3(25 \%)$ & $1(14 \%)$ & \\
\hline Female (\%) & $10(75 \%)$ & $6(86 \%)$ & \\
\hline $\mathrm{BMI}$ & 26 & 24 & 0.26 \\
\hline Age at surgery & 35.36 years & 42.6 years & 0.11 \\
\hline Type of surgery & & & 0.87 \\
\hline SAA $(n=)$ & 10 & 5 & \\
\hline SAA + variation $(n=)$ & 1 & 1 & \\
\hline SAA + valgization $(n=)$ & 1 & 1 & \\
\hline \multicolumn{4}{|l|}{ preoperative PMA score } \\
\hline pain $(/ 6)$ & 2.3 & 1.71 & 0.22 \\
\hline mobility (/6) & 5.5 & 4.7 & 0.07 \\
\hline walking (/6) & 4.4 & 3.6 & 0.1 \\
\hline total (/18) & 12.2 & 10 & 0.13 \\
\hline preoperative Harris score (/100) & 59.4 & 44.2 & $0.048 \dagger$ \\
\hline preoperative Charnley score & & & 0.21 \\
\hline A & $9(60 \%)$ & $2(28.6 \%)$ & \\
\hline B & $6(40 \%)$ & $5(71.4 \%)$ & \\
\hline $\mathrm{C}$ & 0 & 0 & \\
\hline preoperative Devane score & & & 0.19 \\
\hline 5 & $7(46.7 \%)$ & $1(14.3 \%)$ & \\
\hline 4 & $2(13.3 \%)$ & $1(14.3 \%)$ & \\
\hline 3 & $1(6.7 \%)$ & $1(14.3 \%)$ & \\
\hline 2 & $5(33.3 \%)$ & $4(57.1 \%)$ & \\
\hline 1 & & & \\
\hline \multicolumn{4}{|l|}{ preoperative hip radiography } \\
\hline CC'D angle $\left(^{\circ}\right)$ & 133.7 & 131.3 & 0.84 \\
\hline HTE angle $\left(^{\circ}\right)$ & 21.3 & 18.4 & 0.44 \\
\hline VCE angle $\left({ }^{\circ}\right)$ & 13.3 & 17.3 & 0.76 \\
\hline VCA angle $\left(^{\circ}\right)$ & 13.8 & 18 & 0.79 \\
\hline bone matrix abnormalities ( $n=)$ & $1(6.7 \%)$ & $1(14.3 \%)$ & 0.98 \\
\hline osteolysis zones $(n=)$ & $4(26.7 \%)$ & $2(25.6 \%)$ & 0.98 \\
\hline osteosclerosis ( $n=)$ & $6(40 \%)$ & $3(42.9 \%)$ & 0.74 \\
\hline hypoplasia of acetabulum ( $n=$ ) & $13(86.7 \%)$ & $5(71,4 \%)$ & 0.49 \\
\hline Kellgren-Lawrence stage $(\mathrm{n}=)$ & & & 0.2 \\
\hline Stage 0 & $7(46.7 \%)$ & $2(28.6 \%)$ & \\
\hline Stage 1 & $7(46.7 \%)$ & $1(14.3 \%)$ & \\
\hline Stage 2 & $1(6.7 \%)$ & $3(42.9 \%)$ & \\
\hline Stage 3 & 0 & $1(14.3 \%)$ & \\
\hline Stage 4 & 0 & 0 & \\
\hline Crowe stage $(n=)$ & & & 1.0 \\
\hline Stage 1 & 13 & 7 & \\
\hline Stage 2 & 2 & 0 & \\
\hline
\end{tabular}

†significant difference with $\mathrm{p}$ value $<0.05$

score (PMA), ${ }^{10}$ Devane, ${ }^{11}$ and Charnley ${ }^{12}$ scores were calculated preoperatively and, at last, follow up. The SF-12 13 and WOMAC ${ }^{14}$ questionnaires were administered postoperatively.

Patient satisfaction was graded as very satisfied, satisfied, moderately satisfied, or dissatisfied.

Radiology measures were performed before surgery. The severity of hip dysplasia was assessed on:

- the slope of the lateral edge of the acetabular roof $(\mathrm{HTE})^{15}$;

- Wiberg's center-edge (VCE) angle: VCE angle $<20^{\circ}$ is regarded as acetabular dysplasia ${ }^{4}$;

- vertical-center-anterior (VCA) angle ${ }^{16}$;

- femoral neck angle (CC’D).
Osteoarthritis was analyzed on the Kellgren-Lawrence classification. ${ }^{17}$

Preoperative characteristics were compared between the SAA groups with and without THA: gender, age at surgery, PMA, HHS, Devane and Charnley scores, and hip radiography (see Table 1).

Statistics were computed using Stata software, version 12 (StataCorp, College Station, TX, USA). All tests were twosided; $p$-values $<5 \%$ were considered statistically significant. The study sample was described by numbers and percentages for categorical data and by mean \pm standard deviation and range continuous data with non-normal distribution. Normality was assessed graphically and using the Shapiro-Wilk test. Means were compared between preop- 
erative and follow-up values on paired Student t-test. SAA survival was evaluated on Kaplan-Meier survival curves with interval to revision as an event, censored by date of the latest news. Log-rank tests were computed to compare survival between groups.

\section{RESULTS \\ POPULATION}

The study population comprised 23 hips in 21 patients. Twenty-two hips were checked on follow-up. Figure 2 shows the study flowchart. One patient was lost to follow-up (see Figure 2). 7 of the 21 patients underwent THA. The 15 SAA without subsequent THA were checked on clinical and radiological examination. Survival curves are shown in figure 3 (see Figure 3).

\section{SURGERY}

SAA survival in THA was $72.7 \%$ at five years, $36.4 \%$ at ten years, and $13.6 \%$ at 15 years.

Seven hips underwent THA at a mean $6.0 \pm 3.5$ years (range, 1.2-12.6 years). Therefore, the following scores were evaluated for the 15 hips without THA, at a mean of $9.7 \pm$ 5.2 years (range, 2.6-17.4 years).

\section{SCORES}

- Mean increase significantly in PMA score was $2.4 \pm 3.9$ points, increasing from a mean $12.2 \pm 3.1 / 18$ ("poor") before surgery to $14.6 \pm 2.6 / 18$ ("fair") after ( $p=0.03$ ). After surgery, functional results were good in 9 hips, fair in 4, and poor in 2 . The pain component of the PMA score decreased significantly by $1.4 \pm 2.1$ points $(\mathrm{p}=0.02)$, with a corresponding increase in walking distance. Joint ranges of motion were stable, with a mean $82.6-102^{\circ}$ flexion. Walking stability increased with the abandonment of crutches when used. Preoperative PMA scores were worse in patients without THA: $10 / 18 \pm 2.7$ (95\% CI,7.5-12.5) in the SAA+THA group versus $12.2 / 18 \pm 3.1$ (95\% CI, 10.5-13.9) in SAA without subsequent THA ( $\mathrm{p}=0.13$ ) (see Table 1).

- Harris score improved, from a mean $59.4 \pm 15.3 / 100$ (95\% CI, 50.9-67.9] ("poor") before surgery to 68.6 $\pm 16.6 / 100$ (95\% CI, 59.4-77.8) (“good”) after $(\mathrm{p}=0.16)$. HHS pain score improved from $15.3 \pm$ 7.4(95\% CI, $11.2-19.4)$ to $22.9 \pm 12.9(15.8-30.6)$ $(\mathrm{p}=0.12)$; the gait, activity and deformity components showed non-significant change except for extension, which increased from a mean $4 \pm 5.1^{\circ}(95 \% \mathrm{CI}$, $\left.1.2-6.8^{\circ}\right)$ to $7 \pm 5.3^{\circ}\left(95 \% \mathrm{CI}, 4.1-9.9^{\circ}\right)(\mathrm{p}=0.045)$ and internal rotation, with $23 \pm 12.8^{\circ}\left(95 \% \mathrm{CI}, 15.9-30.1^{\circ}\right)$ and $\quad 13.7 \pm 6.7^{\circ}\left(95 \% \quad \mathrm{CI}, \quad 10-17.4^{\circ}\right)$ respectively $(p=0.0442)$. Range of motion was stable for flexion, with pre- and post-operative values $96 \pm 24.1^{\circ}$ (95\% $\left.\mathrm{CI}, 82.6-109^{\circ}\right)$ and $94.7 \pm 14.1^{\circ}\left(95 \% \mathrm{CI}, 86.9-102^{\circ}\right)$ respectively $(\mathrm{p}=0.83)$; adduction, with $20 \pm 7.6^{\circ}(95 \%$ CI, $\left.15.8-24.2^{\circ}\right)$ and $20.7 \pm 7.04^{\circ}\left(95 \% \mathrm{CI}, 16.8-24.6^{\circ}\right)$ respectively $(\mathrm{p}=0.79)$; abduction, with $28 \pm 11.6$ ${ }^{\circ}\left(21.6-34.4^{\circ}\right)$ and $28.7 \pm 11.1^{\circ}\left(95 \%\right.$ CI, $\left.22.5-34.8^{\circ}\right)$ respectively $(\mathrm{p}=0.79)$; and external rotation, with $23 \pm$
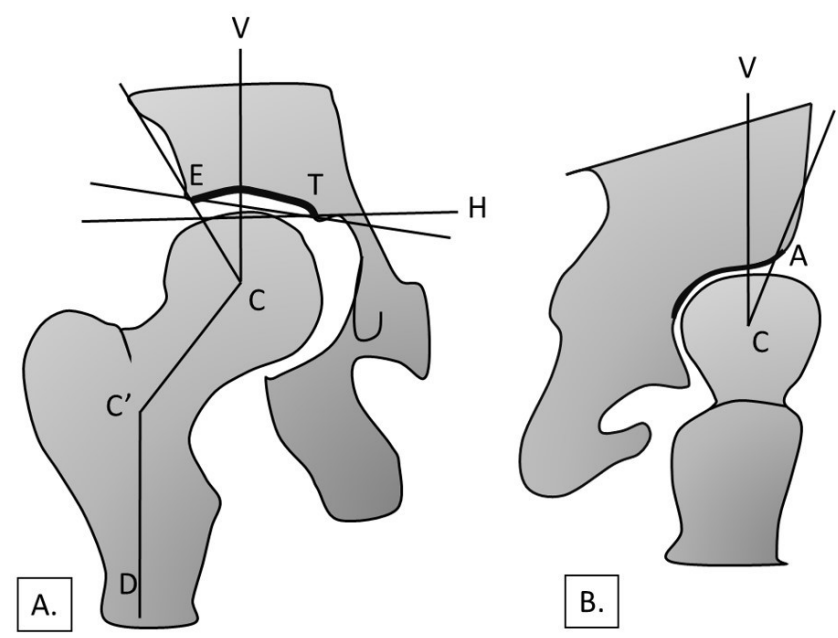

B.

Figure 1. Representation of the basic angles in the adult radiographic hip

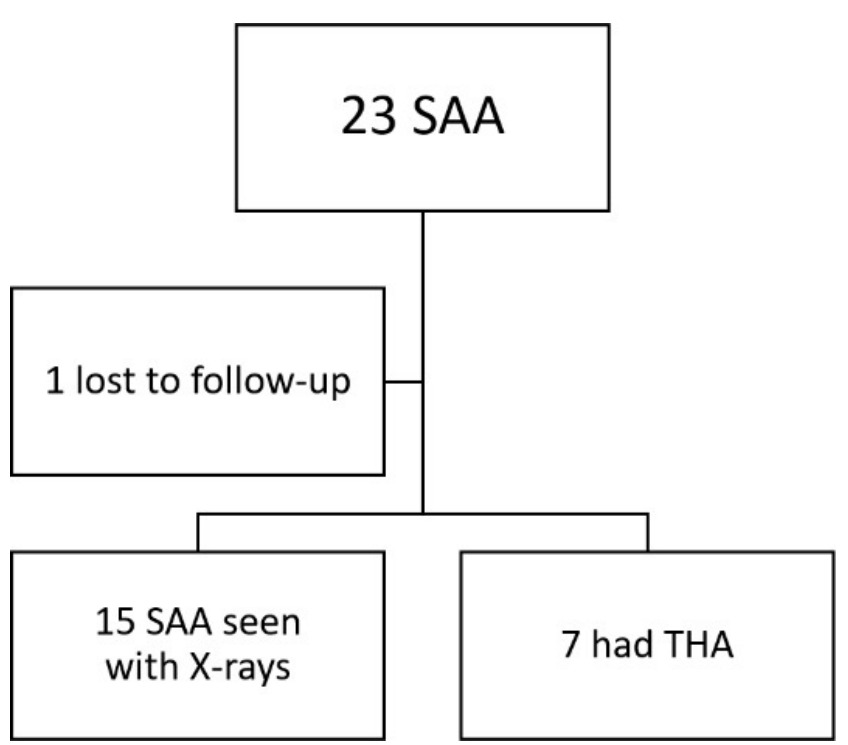

Figure 2. Flow-chart

$11^{\circ}\left(17-29.1^{\circ}\right)$ and $22.7 \pm 10.5^{\circ}\left(95 \% \mathrm{CI}, 17-28^{\circ}\right)$ respectively $(\mathrm{p}=0.92)$. There was a significant difference at baseline between the group with SAA without subsequent THA and the SAA+THA group for preoperative HHS score: $59.4 \pm 15.4$ (95\% CI, 50.9-67.9) and 44.2 \pm 6.1 (95\% CI, 29.3-59.1) respectively ( $\mathrm{p}=0.052$ ) (see Table 1).

- No patient had pain at the iliac engraftment at the last follow-up.

- Charnley's score was stable: 9 SAA grade A (pain affected the unilateral hip) and 6 grade B (pain affected both hips) before surgery, and 7 grade $A$ and 8 grade $B$ after surgery $(p=0.33)$ (see Table 2). There was no significant difference at baseline between the group with SAA without subsequent THA and the SAA+THA group for preoperative pain $(\mathrm{p}=0.21)$ (see Table 1).

- Devane activity score was stable after SAA ( $p=0.23)$ : 
Table 2. Evolution in pre and post-operative characteristics of the 15 SAAs without THA at the last followed up

\begin{tabular}{|c|c|c|c|}
\hline Characteristics & before & after & P-value \\
\hline \multicolumn{4}{|l|}{ PMA score } \\
\hline pain (/6) & 2.3 & 3.7 & $0.02 \dagger$ \\
\hline mobility (/6) & 5.5 & 5.7 & 0.30 \\
\hline walking (/6) & 4.4 & 5.1 & 0.09 \\
\hline total (/18) & 12.2 & 14.6 & $0.03 \dagger$ \\
\hline Harris score $(/ 100)$ & 59.4 & 68.6 & 0.16 \\
\hline Charnley score & & & 0.33 \\
\hline A & $9(60 \%)$ & $7(46.7 \%)$ & \\
\hline B & $6(40 \%)$ & $8(53.3 \%)$ & \\
\hline C & 0 & 0 & \\
\hline Devane score & & & 0.23 \\
\hline 5 & $7(46.7 \%)$ & $4(26.7 \%)$ & \\
\hline 4 & 2 (13.3\%) & $2(13.3 \%)$ & \\
\hline 3 & $1(6.7 \%)$ & $4(26.7 \%)$ & \\
\hline 2 & $5(33.3 \%)$ & $5(33.3 \%)$ & \\
\hline 1 & 0 & 0 & \\
\hline \multicolumn{4}{|l|}{ Hip radiography } \\
\hline bone matrix abnormalities ( $n=)$ & $1(6.7 \%)$ & $1(6.7 \%)$ & 1 \\
\hline osteolysis zones ( $n=)$ & $4(26.7 \%)$ & $4(26.7 \%)$ & 1 \\
\hline osteosclerosis (n=) & $6(40 \%)$ & $6(40 \%)$ & 1 \\
\hline hypoplasia of acetabulum ( $\mathrm{n}=$ ) & $13(86.7 \%)$ & $13(86.7 \%)$ & 1 \\
\hline Kellgren-Lawrence stage $(\mathrm{n}=)$ & & & 0.06 \\
\hline Stage 0 & $7(46.7 \%)$ & $5(33.3 \%)$ & \\
\hline Stage 1 & $7(46.7 \%)$ & $7(46.7 \%)$ & \\
\hline Stage 2 & $1(6.7 \%)$ & $2(13.3 \%)$ & \\
\hline Stage 3 & 0 & $1(6.7 \%)$ & \\
\hline Stage 4 & 0 & 0 & \\
\hline
\end{tabular}

†significant difference with $\mathrm{p}$ value $<0.05$

seven SAA with a score of 5 , two with four and one with three before surgery, and four with a score of 2 , two with 4, four with three, and five with two after surgery (see Table 2). There was no significant difference between the groups with SAA without subsequent THA and the SAA+THA group in preoperative Devane score (SAA+THA group: one patient with a score of 5 , one with 4 , one with 3 , four with 2$)(p=0.19)$ (see Table 1).

- The mean SF12 quality of life score was $11.5 \pm 2.2$ (range, 8-16) for the physical component, $17 \pm 3.2$ (9-20) for the mental component, and $28.5 \pm 3.6$ (range, 21-33) for the total score.

- The mean WOMAC total score was moderate: $38.1 \pm$ $12.1 / 100$ (range, 7.3-52.1)). The pain component was $8.6 \pm 3.4 / 20$ (1-13), and the physical function component $27.9 \pm 8.9 / 68(6-37)$. Stiffness was more severe: $2.9 \pm 1.3 / 8(1-5)$.

Satisfaction with surgery was mainly reasonable, with six patients very satisfied, six satisfied, three moderately satisfied, and four dissatisfied. There was a trend for dissatisfaction in patients with a short interval ( $<5$ years) to THA.

Hip angles were assessed on radiography before surgery, at one year and last follow-up for the 15 hips without THA:

There was no significant difference between the groups with and without subsequent THA in preoperative hip angles (see Table 1).

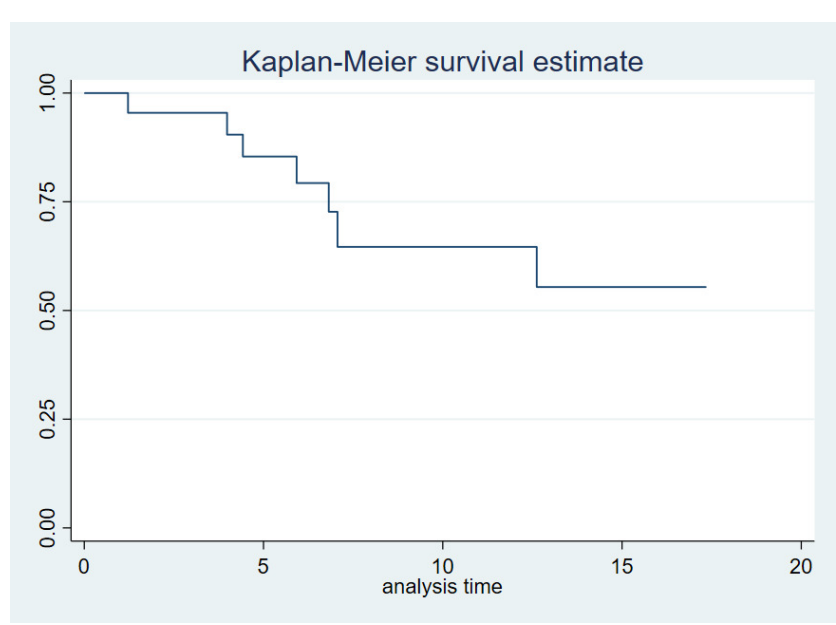

Figure 3. Kaplan-Meier survival estimate for SAA (in years)

\section{RADIOGRAPHIC ABNORMALITIES}

- Follow-up radiographs were available for 15 SAAs without subsequent THA.

- Based on the Kellgren-Lawrence classification, there was no radiographic difference between the preoperative and the first-year evaluation. However, there were some differences between preoperative data and data at the follow-up consultation (see Figure 4):

- of the 9 stage 0 SAAs, five remained stable, two 
progressed to stage 1, 2 were revised with THA

- of the 9 stage 1 SAAs, 5 remained stable, 1progressed to stage 2, 1 progressed to stage 3,1 was revised with THA, and one was lost to follow-up.

- Of the 4 stage 2 SAAs, only 1 remained stable, while the other three were revised with THA.

- The 1 stage 4 SAA was also revised with THA.

Of patients with THA, two were stage 0 , one was stage 1 , three were stage 2 , and one was stage 4 before SAA.

There was no progression for the other radiographic criteria: abnormalities of the bone matrix, presence of osteolysis zones, or osteosclerosis before or after surgery. There was no protrusion of the acetabulum on hip radiographs. (see Table 2)

There were no significant differences in preoperative radiographic abnormalities between the group with SAA without subsequent THA and the SAA+THA group (see Table 1).

\section{DISCUSSION}

The study hypothesis was validated: SAA survival was $72.7 \%, 36.4 \%$, and $13.6 \%$ at 5,10 , and 15 years, respectively. Most patients were satisfied with their surgery; only four were not. Clinical scores (WOMAC, SF12) were moderate but were improved by the surgical procedure. Functional scores (PMA and HHS) improved significantly with SAA. Radiological evaluation showed no significant progression of osteoarthritis.

Many hip-shelf procedures have been described. Longterm results of conservative Chiari osteotomy for hip dysplasia are available, as this procedure has been performed for 50 years. Kotz et al. reported conversion to THA in 32 out of 80 hips (40\%), at a mean interval between pelvic osteotomy and THA of 26 years (range, 13-41 years). ${ }^{18} \mathrm{Mi}$ gaud et al., in 89 hips undergoing conservative surgery (pelvic osteotomy with shelf ${ }^{19}$ or Chiari procedure), reported $84 \%$ survival (95\% CI,80\% - 88\%) at 10 years, and $68 \%$ (95\% CI, $54 \%$ - 81\%)at 18 years. ${ }^{20}$ These studies were performed at least ten years ago, and the present study refreshes the results. There were no significant differences between the group with SAA without subsequent THA and the SAA+THA group (see Table 1).

SAA is a more recent technique, first described by Staheli and performed for 20 years now. ${ }^{6} \mathrm{Su}$ et al. ${ }^{21}$ and Fong et $a l .{ }^{22}$ reported that none of their 16 hips required conversion to joint replacement at a mean 6.6 years (1-12.3 years) and 4.1 years 'follow-up, respectively. However, these were short follow-ups that do not necessarily allow comparison of survival for SAA.

The present functional results are consistent with those of Pompe et al., ${ }^{23}$ who studied 14 hips with SAA and reported an increase in HHS from 60/100 to $93 / 100$ at a mean four years' follow-up, and of Su et al., ${ }^{21}$ who reported a rise in HHS from 74.7 to 92.7 at a mean 6.6 years' follow-up (range, 1-12.3 years) in 16 hips with SAA. The main improvement was in pain, and these two studies considered SAA an effective treatment for painful residual dysplastic hip in adolescents and young adults.

Unfortunately, there were several biases in the present

\section{preoperative Last follow-up}

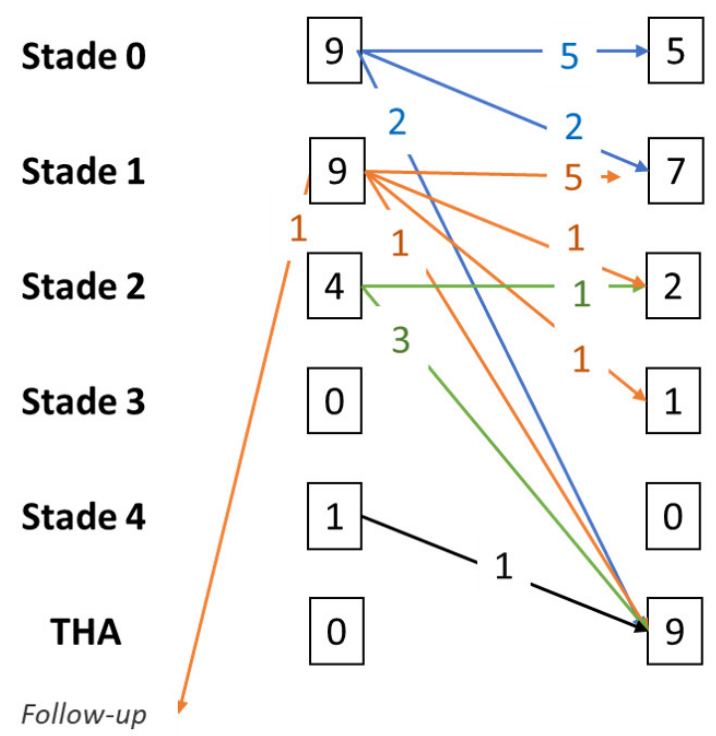

Figure 4. Progression of Kellgren-Lawrence
radiological stage

The number of hips radiologically assessed before SAA and at the time of consultation. Arrows show the passage from one stage to another.

study. First, hip dysplasia in adults is becoming rare because of improvement in the management of childhood dysplasia. Risk factors are known, and an international survey of pediatric orthopedic surgeons found a consensus in favor of clinical examination to diagnose developmental hip dysplasia in early infancy. ${ }^{24}$ Ultrasound enables earlier neonatal screening, ${ }^{25}$ with early treatment by Pavlik harness, ${ }^{26}$ for example. The present study was retrospective, and possible memory bias in the subjective evaluation of the quality of life is to be considered.

Migaud et al. ${ }^{27}$ reported that conservative surgery (pelvic osteotomy with shelf ${ }^{19}$ or Chiari procedure) for congenital dysplasia of the hip did not impair subsequent THA's functional results or survivorship. Duncan et al. ${ }^{28}$ drew the same conclusions from a systematic review of 10 studies, including 1,167 patients with pelvic and/or femoral osteotomy but no SAA.

We could imagine supplementing the present results by analyzing the influence of SAA on the functional and survival scores of THA when this is subsequently performed. SAA is still a solution that can be proposed to a dysplastic patient.

\section{CONCLUSIONS}

The present patients were young in case of low-grade (Crowe stage 1 or 2) hip dysplasia. This kind of conservative surgery allowed them to recover the acceptable quality of life, less pain, conserved autonomy, and physical and occupational activity. These results encourage us not to abandon SAA in luxating hip disease, even if total hip arthroplasty is considered in the longer term. 
Submitted: May 01, 2021 EST, Accepted: May 14, 2021 EST 


\section{REFERENCES}

1. Clohisy JC, Dobson MA, Robison JF, et al.

Radiographic structural abnormalities associated with premature, natural hip-joint failure. J Bone Joint Surg Am. 2011;93 Suppl 2:3-9. doi:10.2106/IB/S.J.01734

2. Crowe JF, Mani VJ, Ranawat CS. Total hip replacement in congenital dislocation and dysplasia of the hip. J Bone Jt Surg. 1979;61(1):15-23.

3. Stulberg SD, Harris WH. Acetabular dysplasia and development of osteoarthritis of hip. Harris WH, ed. The hip Proceedings of the Second Open Scientific Meeting of the Hip Society. Published online 1974:82.

4. Wiberg G. Studies on dysplastic acetabula and congenital subluxation of the hip joint. Acta Orthopaedica Scandinavica. Supplementum. 1939:1-132.

5. Dunlap K, Penner RS, Swanson AB. Studies of the hip joint by means of lateral acetabular roentgenograms. J Bone Joint Surg Am. 1956;38-A(6):1218-1230.

6. Staheli LT. Slotted acetabular augmentation. $J$ Pediatr Orthop. 1981;1(3):321-327.

7. Muhamad Effendi F, Shin CH, Park MS, Yoo WJ, Choi IH, Cho TJ. Step-cut Valgus Osteotomy of Proximal Femur. Tech Orthop. 2017;32(3):179. doi:1 0.1097/BTO.0000000000000228

8. Rozkydal Z, Kovanda M. Chiari pelvic osteotomy in the management of developmental hip dysplasia: a long term follow-up. Bratisl Lek Listy. 2003;104(1):7-13.

9. Harris WH. Traumatic arthritis of the hip after dislocation and acetabular fractures: treatment by mold arthroplasty. An end-result study using a new method of result evaluation. J Bone Joint Surg Am. 1969;51(4):737-755.

10. D’aubigne RM, Postel M. Functional results of hip arthroplasty with acrylic prosthesis. J Bone Joint Surg Am. 1954;36-A(3):451-475.

11. Devane PA, Horne JG, Martin K, Coldham G, Krause B. Three-dimensional polyethylene wear of a press-fit titanium prosthesis. Factors influencing generation of polyethylene debris. J Arthroplasty. 1997;12(3):256-266.

12. Charnley J. The long-term results of low-friction arthroplasty of the hip performed as a primary intervention. J Bone Joint Surg Br. 1972;54(1):61-76.
13. Ware J, A. Kosinski M, D. Keller S. SF-12: How to Score the SF-12 Physical and Mental Health Summary Scales. Published online 1998.

14. Bellamy N, Buchanan WW, Goldsmith CH, Campbell J, Stitt LW. Validation study of WOMAC: a health status instrument for measuring clinically important patient relevant outcomes to antirheumatic drug therapy in patients with osteoarthritis of the hip or knee. J Rheumatol. 1988;15(12):1833-1840.

15. Murray DW. The definition and measurement of acetabular orientation. J Bone Joint Surg Br. 1993;75(2):228-232.

16. Lequesne M, de SEZE. False profile of the pelvis. A new radiographic incidence for the study of the hip. Its use in dysplasias and different coxopathies. Rev Rhum Mal Osteoartic. 1961;28:643-652.

17. Steadman JR, Briggs KK, Matheny LM, Ellis HB. Ten-year survivorship after knee arthroscopy in patients with Kellgren-Lawrence grade 3 and grade 4 osteoarthritis of the knee. Arthrosc. 2013;29(2):220-225. doi:10.1016/j.arthro.2012.08.018

18. Kotz R, Chiari C, Hofstaetter JG, Lunzer A, Peloschek P. Long-term Experience with Chiari's Osteotomy. Clin Orthop. 2009;467(9):2215-2220. do $\mathrm{i}: 10.1007 / \mathrm{s} 11999-009-0910-\mathrm{y}$

19. Milch H. The "pelvic support” osteotomy. 1941. Clin Orthop. 1989;(249):4-11.

20. Migaud H, Chantelot C, Giraud F, Fontaine C, Duquennoy A. Long-term survivorship of hip shelf arthroplasty and Chiari osteotomy in adults. Clin Orthop. 2004;(418):81-86.

21. Su YP, Wang MNH, Chang WN. Slotted acetabular augmentation in the treatment of painful residual dysplastic hips in adolescents and young adults. $J$ Formos Med Assoc. 2008;107(9):720-727. doi:10.1016/ $\underline{\text { S0929-6646(08)60117-5 }}$

22. Fong HC, Lu W, Li YH, Leong JC. Chiari osteotomy and shelf augmentation in the treatment of hip dysplasia. J Pediatr Orthop. 2000;20(6):740-744.

23. Pompe B, Antolic V. Slotted acetabular augmentation for the treatment of residual hip dysplasia in adults: early results of 12 patients. Arch Orthop Trauma Surg. 2007;127(8):719-723. doi:10.100 7/s00402-007-0338-3 
24. Roposch A, Liu LQ, Hefti F, Clarke NMP, Wedge JH. Standardized diagnostic criteria for developmental dysplasia of the hip in early infancy. Clin Orthop. 2011;469(12):3451-3461. doi:10.1007/s11 999-011-2066-9

25. Eastwood DM. Neonatal hip screening. Lancet. 2003;361(9357):595-597. doi:10.1016/S0140-6736(0 3)12519-6

26. Taylor GR, Clarke NM. Monitoring the treatment of developmental dysplasia of the hip with the Pavlik harness. The role of ultrasound. J Bone Joint Surg Br. 1997;79(5):719-723.
27. Migaud H, Putman S, Berton C, et al. Does prior conservative surgery affect survivorship and functional outcome in total hip arthroplasty for congenital dislocation of the hip? A case-control study in 159 hips. Orthop Traumatol Surg Res. 2014;100(7):733-737. doi:10.1016/j.otsr.2014.07.016

28. Duncan S, Wingerter S, Keith A, Fowler SA, Clohisy J. Does previous osteotomy compromise total hip arthroplasty? A systematic review. J Arthroplasty. 2015;30(1):79-85. doi:10.1016/j.arth.2014.08.030 